\title{
Preventive Stitching for Migration of a Peritoneal Catheter Into the Abdominal Wall After Ventriculoperitoneal Shunting
}

\author{
-Technical Note-
}

\author{
Kuniaki NAKAHARA, Satoru SHIMIZU, Hidehiro OKA, \\ Satoshi UTSUKI, and Kiyotaka FUJII
}

Department of Neurosurgery, Kitasato University School of Medicine, Sagamihara, Kanagawa

\begin{abstract}
Migration of the distal end of a ventriculoperitoneal shunt into the abdominal wall (epi-peritoneal layer) is a complication which is especially likely in obese patients with high intra-abdominal pressure and wide dead space around the catheter remaining after laparotomy. A preventive abdominal stitching method for this complication was developed consisting of sutures beside the catheter penetrating the peritoneum, posterior and anterior sheath of rectus abdominis muscle, and subcutaneous fat. This method was applied to more than 20 patients who underwent ventriculoperitoneal shunting. No patient experienced shunt migration. The technique is easy and safe to perform, avoids leaving a dead space around the peritoneal catheter, and prevents catheter migration.
\end{abstract}

Key words: abdominal wall, migration, obesity, peritoneal catheter, ventriculoperitoneal shunt

\section{Introduction}

Ventriculoperitoneal shunt surgery is very common but may cause various types of complications. Migration of the peritoneal catheter into the abdominal wall, that is the epi-peritoneal layer, is a complication of the distal end of the catheter which results in malfunction of the shunt with pooling of cerebrospinal fluid in the abdominal wall. Repositioning of the migrated catheter is possible, ${ }^{1,2,4-6,9)}$ but corrective measures have not been detailed. We have developed a preventive abdominal stitching method for this complication.

\section{Technical Method}

The preventive abdominal stitching method has been applied to more than 20 obese adults who underwent standard ventriculoperitoneal shunt for hydrocephalus since 2007. At placement of the peritoneal catheter, a pararectal transverse incision with a length of $3-5 \mathrm{~cm}$ is made, and the abundant fat is retracted to obtain an adequate field for laparotomy. The anterior sheath of the rectus abdominis muscle, the belly of the muscle, and the posterior sheath of the muscle are divided, and a small opening is made in the peritoneum. The direction of division of the sheaths and the peritoneum is transverse, that is vertical to the peritoneal catheter. A hydrogel-processed peritoneal catheter (Bioglide; Medtronic, Minneapolis, Minn.,

Received September 8, 2009; Accepted January 8, 2010
U.S.A.) is inserted into the peritoneal cavity through the opening of the peritoneum. A non-absorbable suture is applied to the peritoneum as close as possible to both sides of the catheter, and is knotted. The applied suture is attached to a needle to penetrate the layers overlying the peritone$\mathrm{um}$, that is the posterior and anterior sheath of rectus abdominis muscle, and the subcutaneous fat approximately $1 \mathrm{~cm}$ superficial to the catheter. After penetrating those

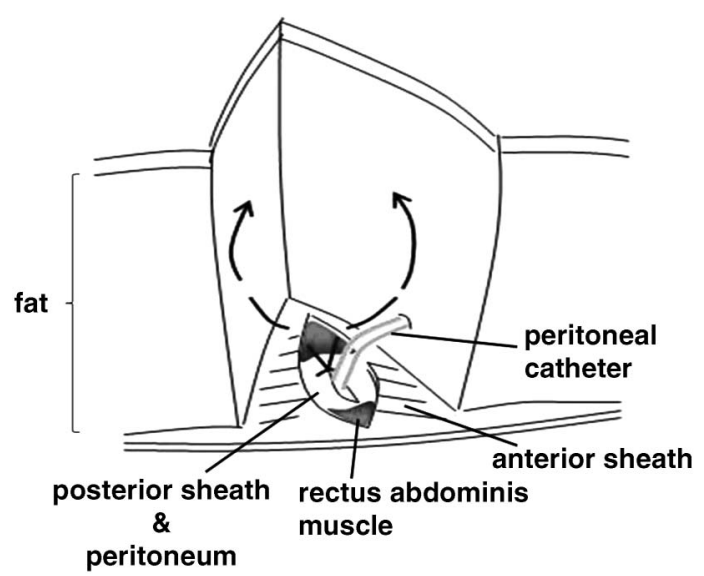

Fig. 1 Schematic showing the suture beside the peritoneal catheter which penetrates the peritoneum, posterior and anterior sheath of rectus abdominis muscle, and subcutaneous fat to prevent formation of dead space. 
layers, the sutures beside the catheter are knotted, thus forming an artificial sheath surrounding the catheter, which avoids migration of the catheter into a dead space in the abdominal wall (Fig. 1). The subcutaneous layer and skin are closed in standard fashion.

The artificial sheath can be formed in less than 5 minutes. No migration was experienced during the followup period of 1-26 months. No technique-related complications, such as obstruction of the catheter or pain of the wound, were encountered.

\section{Discussion}

Migration of the peritoneal catheter into the preperitoneal space is known in a few cases, ${ }^{9)}$ and we have experienced such a case. ${ }^{4)}$ This migration has multiple causes. The epiperitoneal dead spaces including the space between two layers of the fascia, and that between the anterior layer of fascia and the subcutaneous fat, are preserved by laparotomy. The space tends to be large in obese patients due to the excessive retraction to obtain an adequately large field for laparotomy. Excessively increased intraabdominal pressure may push out the peritoneal catheter which migrates into the dead spaces.

Normally, intra-abdominal pressure is atmospheric $(0$ $\mathrm{mmHg})$ or slightly subatmospheric $\left.(<0 \mathrm{mmHg})^{3,7,10}\right)$ However, measurement of intra-abdominal pressure with a transurethral bladder catheter in 84 morbidly obese patients found that higher sagittal abdominal diameter was associated with significant increase in this pressure. ${ }^{8)}$ Intra-abdominal pressure was well above $8 \mathrm{mmHg}$ and could be as high as $12 \mathrm{mmHg}$ in some obese patients. In addition, the use of a hydrogel-processed peritoneal catheter covered with hydrogel may have contributed to the catheter migration. These catheters become hydrophilic and slippery when hydrated, resulting in low friction between the catheters and surrounding tissue, so increasing the possibility of migration.

The present method is easy and safe to perform, and the preventive stitching is effective to avoid catheter migration by closing the entry of the dead space around the catheter.

\section{References}

1) Besson R, Hladky JP, Dhellemmes P, Debeugny P: Peritoneal pseudocyst-Ventriculo-peritoneal shunt complications. Eur J Pediatr Surg 5: 195-197, 1995

2) Gutierrez FA, Raimondi AJ: Peritoneal cysts: A complication of ventriculoperitoneal shunts. Surgery 79: 188-192, 1976

3) Malbrain ML, Cheatham ML, Kirkpatrick A, Sugrue M, Parr M, De Waele J, Balogh Z, Leppaniemi A, Olvera C, Ivatury R, D'Amours S, Wendon J, Hillman K, Johansson K, Kolkman $\mathrm{K}$, Wilmer A: Results from the international conference of experts on intra-abdominal hypertension and abdominal compartment syndrome. I. Definitions. Intensive Care Med 32: 1722-1732, 2006

4) Nakahara K, Shimizu S, Oka H, Utsuki S, Iida H, Fujii K: Migration of the distal end of a ventriculoperitoneal shunt into the abdominal wall in an obese patient: case report. Neurol Med Chir (Tokyo) 49: 490-492, 2009

5) Nfonsam V, Chand B, Rosenblatt S, Turner R, Luciano M: Laparoscopic management of distal ventriculoperitoneal shunt complications. Surg Endosc 22: 1866-1870, 2008

6) Rainov N, Schobess A, Heidecke V, Burkert W: Abdominal CSF pseudocysts in patients with ventriculoperitoneal shunts. Report of fourteen cases and review of the literature. Acta Neurochir (Wien) 127: 73-78, 1994

7) Sanchez NC, Tenofsky PL, Dort JM, Shen LY, Helmer SD, Smith RS: What is normal intra-abdominal pressure? Am Surg 67: 243-248, 2001

8) Sugerman H, Windsor A, Bessos M, Kellum J, Reines H, DeMaria E: Intra-abdominal pressure, sagittal abdominal diameter and obesity comorbidity. J Intern Med 241: 71-79, 1997

9) Turner R, Chahlavi A, Rasmussen P, Brody F: Laparoscopic revision of a ventriculoperitoneal shunt. J Laparoendosc Adv Surg Tech A 14: 310-312, 2004

10) Yol S, Kartal A, Tavli S, Tatkan Y: Is urinary bladder pressure a sensitive indicator of intra-abdominal pressure? Endoscopy 30: 778-780, 1998

Address reprint requests to: Kuniaki Nakahara, M.D., Department of Neurosurgery, Kitasato University School of Medicine, 1-15-1 Kitasato, Sagamihara, Kanagawa 228-8555, Japan. e-mail:nakahara19@hotmail.com 